\title{
p300/CBP histone acetyltransferase activity is required for newly acquired and reactivated fear memories in the lateral amygdala
}

\author{
Stephanie A. Maddox, ${ }^{1}$ Casey S. Watts, ${ }^{1}$ and Glenn E. Schafe ${ }^{1,2,3}$ \\ ${ }^{1}$ Department of Psychology, Yale University, New Haven, Connecticut 06520, USA; ${ }^{2}$ Interdepartmental Neuroscience Program, Yale \\ University, New Haven, Connecticut 06520, USA
}

\begin{abstract}
Modifications in chromatin structure have been widely implicated in memory and cognition, most notably using hippocampal-dependent memory paradigms including object recognition, spatial memory, and contextual fear memory. Relatively little is known, however, about the role of chromatin-modifying enzymes in amygdala-dependent memory formation. Here, we use a combination of biochemical, behavioral, and neurophysiological methods to systematically examine the role of p300/CBP histone acetyltransferase (HAT) activity in the consolidation and reconsolidation of auditory Pavlovian fear memories. We show that local infusions of c646, a selective pharmacological inhibitor of p300/CBP activity, shortly following either fear conditioning or fear memory retrieval impair training and retrieval-related regulation of histone acetylation in the lateral nucleus of the amygdala (LA). Furthermore, we show that intra-LA infusion of c646 significantly impairs fear memory consolidation, reconsolidation, and associated neural plasticity in the LA. Our findings collectively suggest that p300/CBP HAT activity is critical for the consolidation and reconsolidation of amygdala-dependent Pavlovian fear memories.
\end{abstract}

Traditional views of mammalian memory formation and consolidation have emphasized the necessity of NMDA-receptormediated activation of protein kinase signaling cascades, the recruitment of transcription factors, and associated changes in gene expression that are thought to be critical for long-term memory and synaptic plasticity (Milner et al. 1998; Barco et al. 2006). Pavlovian fear conditioning, for example, has been shown to involve NMDAR-driven alterations in synaptic transmission within the lateral nucleus of the amygdala (LA) (Miserendino et al. 1990; Rodrigues et al. 2001) and the resultant activation of protein kinase signaling pathways (Schafe et al. 1999, 2000; Moita et al. 2002), transcription factors (Josselyn et al. 2001), and the expression of early and late response genes (Ressler et al. 2002; Malkani et al. 2004; Ploski et al. 2008, 2010; Maddox et al. 2011) in LA neurons. With few exceptions (Alberini 2005), a similar molecular framework has been observed to underlie the "reconsolidation" of Pavlovian fear memories in the LA (Dudai and Eisenberg 2004; Duvarci et al. 2005, 2008; Ben Mamou et al. 2006; Tronson et al. 2006; Tronson and Taylor 2007; Maddox and Schafe 2011a; Maddox et al. 2011).

Within the last decade, it has become increasingly clear that so-called epigenetic mechanisms, including modifications of chromatin structure and DNA methylation, play an additional critical role in transcriptional regulation, synaptic plasticity, and memory formation (Levenson and Sweatt 2005, 2006; Barrett and Wood 2008; Jiang et al. 2008). Chromatin, consisting of DNA tightly packaged around a core of eight histone proteins, is known to be post-translationally regulated by the acetylation of lysine residues on the N-terminus histone tails via histone acetyltransferases (HATs). The acetylation of lysine residues by HATs promotes the relaxation of chromatin to facilitate transcription factor binding and enhances transcription (Varga-Weisz and

\footnotetext{
${ }^{3}$ Corresponding author

E-mail glenn.schafe@yale.edu

Article is online at http://www.learnmem.org/cgi/doi/10.1101/Im.029157.112.
}

Becker 1998; Yang and Seto 2007). While many proteins have been demonstrated to possess HAT activity, three have been most widely categorized and studied in the context of memory processes, including CREB-binding protein (CBP), E1A-associated protein (p300), and the p300/CBP-associated factor (PCAF). To date, the majority of studies examining the requirement of these HATs in memory processes have focused on p300/CBP using knock-out models in the context of hippocampal-dependent memory paradigms, including object recognition, spatial memory, and contextual fear memory (Korzus et al. 2004; Wood et al. 2005, 2006; Oliveira et al. 2007, 2011; Vecsey et al. 2007; Barrett et al. 2011; Valor et al. 2011). Surprisingly, however, only two studies have to date reported a deficit in amygdala-dependent "cued" memory formation in a CBP knock-out (Oike et al. 1999; Alarcon et al. 2004), while most have found no effect (Korzus et al. 2004; Wood et al. 2005, 2006; Oliveira et al. 2007, 2011; Valor et al. 2011). Collectively, these findings suggest that a closer examination of the contribution of HATs, and p300/CBP in particular, in amygdala-dependent fear memories is warranted.

Our laboratory has recently observed that both auditory Pavlovian fear conditioning and retrieval of an auditory fear memory regulate histone acetylation in the LA (Maddox and Schafe 2011b; Monsey et al. 2011). Furthermore, we have shown that intra-LA infusion of an inhibitor of histone deacetylase (HDAC) activity enhances both fear memory consolidation and reconsolidation (Maddox and Schafe 2011b; Monsey et al. 2011). In the present study, we sought to examine the role of p300/CBP HAT activity in amygdala-dependent memory consolidation and reconsolidation processes using c646, a specific inhibitor of p300/CBP HAT activity (Bowers et al. 2010). We show that intra-LA infusion of c646 impairs training- and retrieval-related regulation of histone acetylation in the LA. Furthermore, we show that intra-LA infusion of c646 at or near the time of training or retrieval impairs auditory fear memory consolidation and reconsolidation, respectively, as well as memory-related synaptic plasticity in the LA. 


\section{Results}

Intra-LA infusion of an inhibitor of p300/CBP histone acetyltransferase activity impairs fear memory consolidation

In our first experiment, we examined whether p300/CBP HAT activity is necessary for training-related regulation of histone acetylation and fear memory consolidation in the LA. Rats were fear-conditioned with three pairings of a tone (conditioned stimulus; CS) with footshock (unconditioned stimulus; US) followed $1 \mathrm{~h}$ later by intra-LA infusion of either Vehicle $(0.5 \mu \mathrm{L} /$ side $)$ or c646 (500 ng/side; $0.5 \mu \mathrm{L})$. A number of the rats were sacrificed $30 \mathrm{~min}$ later (90 min following training) to examine the effect of c646 on the training-related acetylation of histone $\mathrm{H} 3$ in the LA (Fig. 1A). This time point was chosen based on our previous observation that auditory fear conditioning leads to an increase in histone $\mathrm{H} 3$ acetylation that is most prominent at $90 \mathrm{~min}$ following training (Monsey et al. 2011). The remaining rats received tests of short-term memory (STM) and long-term memory (LTM) in a distinct chamber at $3 \mathrm{~h}$ and $21 \mathrm{~h}$ following infusion, respectively (Fig. 1A).

Intra-LA infusion of c646 following tone-shock pairings resulted in a reduction in acetylation of histone $\mathrm{H} 3\left(\mathrm{AcH} 3 ; F_{(2,20)}=\right.$ 18.0, $P<0.05$ ) (Fig. 1B). Duncan's post-hoc tests revealed that the fear-conditioned-c646 group was significantly different from both the fear-conditioned-Vehicle group $(P<0.05)$ and the na-
ive-Vehicle group $(P<0.05)$. No difference was observed in total protein levels of histone H3 $\left(F_{(2,20)}=0.97\right)$ (Fig. $\left.1 \mathrm{~B}\right)$ or in the loading protein $\operatorname{GAPDH}\left(F_{(2,20)}=1.21, P>0.05\right)$ (data not shown).

In our behavioral experiments, Vehicle- and c646-infused rats exhibited equivalent freezing levels during the STM test $\left(t_{(14)}=1.02\right)$ (Fig. 1C), indicating that c646 has no effect on STM. However, the following day, c646-treated rats exhibited impaired LTM relative to the Vehicle-infused group $\left(t_{(14)}=12.97\right.$, $P<0.01$ ) (Fig. 1C). Furthermore, we found that the effect of c646 on fear memory consolidation is temporally constrained; when rats were given intra-LA infusion of c646 $6 \mathrm{~h}$ following training, there was no effect on LTM $\left(t_{(12)}=0.54\right)$ (Fig. 1C). Thus, intra-LA infusion of c646 within a narrow window $(1 \mathrm{~h})$ following Pavlovian fear conditioning can significantly impair the training related acetylation of histone $\mathrm{H} 3$ in the LA and the consolidation of an auditory Pavlovian fear memory.

\section{Intra-LA infusion of an inhibitor of p300/CBP histone acetyltransferase activity impairs fear memory reconsolidation}

Next, we asked whether local infusion of c646 into the LA shortly after fear memory retrieval can impair the reconsolidation of a fear memory. Rats were fear-conditioned as before followed $24 \mathrm{~h}$ later by a fear memory retrieval (or "reactivation") session
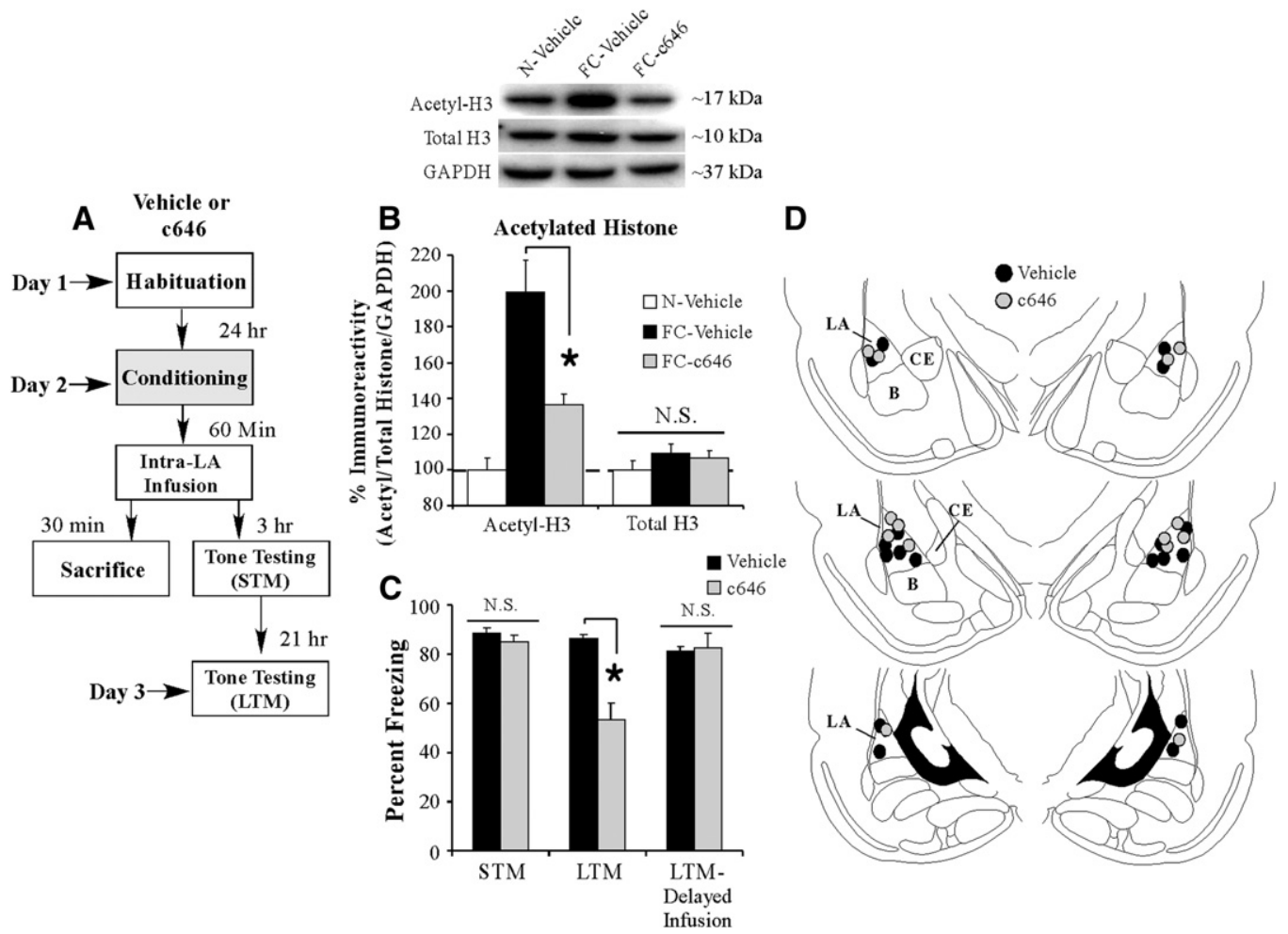

Figure 1. Intra-LA infusion of an inhibitor of $\mathrm{p} 300 / \mathrm{CBP}$ activity impairs training-related acetylation of histone $\mathrm{H} 3$ and fear memory consolidation. ( $A$ ) Schematic of the behavioral protocol. Rats were fear-conditioned with three tone-shock pairings followed $1 \mathrm{~h}$ later by intra-LA infusion of either Vehicle $(n=8)$ or $c 646(500 \mathrm{ng} /$ side; $n=8)$ and were sacrificed 30 min later. A third group did not receive conditioning and was infused with Vehicle before sacrifice $(n=7)$. Separate groups of rats were fear-conditioned with three tone-shock pairings followed $1 \mathrm{~h}$ later by intra-LA infusion of either Vehicle $(n=9)$ or c646 $(500 \mathrm{ng} /$ side; $n=7)$ and tested for STM and LTM 3 and $21 \mathrm{~h}$ later, respectively. (B) Western blot analysis of acetylated and total (nonacetylated) histone $\mathrm{H} 3$ from LA homogenates from naive $(\mathrm{N})$-Vehicle, fear-conditioned (FC)-Vehicle, and FC-c646 groups. $\left({ }^{*}\right) P<0.05$ relative to FCVehicle and N-Vehicle groups. (Inset) Representative Western blots. (C) Mean ( \pm SEM) percent freezing during the STM and LTM tests in Vehicle- and c646-infused groups. A third group is depicted that received infusion of either Vehicle $(n=8)$ or c646 $(n=6) 6 \mathrm{~h}$ following fear conditioning ("delayed infusion") followed by an LTM test $21 \mathrm{~h}$ later. (D) Cannula placements for rats infused with either Vehicle (black circles) or c646 (gray circles). $\left({ }^{*}\right) P<0.05$ relative to Vehicle-infused controls. 
consisting of a single-tone CS presentation. One hour following fear memory reactivation, rats received intra-LA infusion of either Vehicle $(0.5 \mu \mathrm{L} /$ side $)$ or c646 $(500 \mathrm{ng} /$ side; $0.5 \mu \mathrm{L})$. A number of the rats were sacrificed $30 \mathrm{~min}$ later (90 min after retrieval) to examine the effect of c646 on the retrievalrelated acetylation of histone $\mathrm{H} 3$ in the LA (Fig. 2A). This time point was chosen based on our previous observation that retrieval of an auditory fear memory leads to an increase in histone $\mathrm{H} 3$ acetylation that is most prominent at 90 min following retrieval (Maddox and Schafe 2011b). The remaining rats received tests of post-reactivation shortterm memory (PR-STM) and post-reactivation long-term memory (PR-LTM) at $3 \mathrm{~h}$ and $21 \mathrm{~h}$ after infusion, respectively (Fig. 2A).

Intra-LA infusions of c646 significantly impaired retrieval-related regulation of histone H3 acetylation. Analysis of the behavioral data (pre-CS vs. CS freezing) for the Vehicle- and c646-infused groups revealed a significant main effect of Trial $\left(F_{(1,13)}=\right.$ 732.13, $P<0.05)$ but no significant effect of Group $\left(F_{(1,13)}=1.17, P>0.05\right)$, indicating that both groups exhibited significant and equivalent memory retrieval during the reactivation trial (Fig. 2C). Intra-LA infusion of c646 resulted in a significant reduction in retrieval-related acetylation of histone H3 $\quad\left(\right.$ AcH $\left.3 ; \quad F_{(2,19)}=10.0, \quad P<0.05\right)$ (Fig. 2D). Duncan's post-hoc tests revealed that the reactivated-c646 group was significantly different from the reactivated-Vehicle group $(P<0.05)$ yet did not differ from the naive-Vehicle group $(P>0.05)$. Moreover, no difference was observed in total protein levels of histone H3 $\left(F_{(2,19)}=0.17\right)$ (Fig. $2 \mathrm{D})$ or in the loading protein GAPDH $\left(F_{(2,19)}=0.10\right)$ (data not shown).

In our behavioral experiments, both Vehicle- and c646-treated rats exhibited significant and equivalent memory recall during the reactivation session; the ANOVA (Group by Trial) revealed a significant main effect of Trial (pre-CS vs. CS; $F_{(1,15)}=1464.12, P<$ $0.01)$, but no significant main effect of Group $\quad\left(F_{(1,15)}=0.60\right) \quad$ (Fig. 2E). Furthermore, both groups exhibited equivalent levels of freezing during the PR-STM test $\left(t_{(15)}=0.5\right)$ (Fig. $2 \mathrm{~F}$ ), indicating that $\mathrm{c} 646$ has no effect on the retention of a fear memory when the animals are tested shortly after memory reactivation and infusion. However, the following day, c646-treated rats exhibited impaired PR-LTM compared with the Vehicle group $\left(t_{(15)}=11.11, P<0.01\right)$ (Fig. $2 \mathrm{~F}$ ). Furthermore, similar to that observed in our consolidation experiments, we found that the effect of c646 on fear memory reconso- lidation is temporally constrained; when rats were given intra-LA infusion of c646 $6 \mathrm{~h}$ following memory reactivation, there was no effect on PR-LTM $\left(t_{(13)}=0.43\right)$ (Fig. 2F). Thus, intra-LA infusion of c646 within a narrow window $(1 \mathrm{~h})$ following fear memory retrieval can significantly impair retrieval-related acetylation of histone $\mathrm{H} 3$ in the LA and the reconsolidation of a fear memory. 
The reconsolidation deficit produced by c646 is specific to a reactivated fear memory

Importantly, in a separate experiment, we observed that the reconsolidation disruption produced by c646 is specific to a reactivated memory. Rats were fear-conditioned as before, followed $24 \mathrm{~h}$ later by a "no-reactivation" session in which they were placed in the testing context without a tone presentation. One hour following the "no-reactivation" session, rats received intra-LA infusion of either Vehicle $(0.5 \mu \mathrm{L})$ or c646 $(500 \mathrm{ng} / \mathrm{side}$; $0.5 \mu \mathrm{L}$ ) followed 3 and $21 \mathrm{~h}$ later by tests of "PR"-STM and "PR"-LTM (Fig. 2A). Analysis of the reactivation session data revealed that both groups showed equivalently low levels of freezing during the "pre-CS" period and during the 30-sec period when the tone would have been presented during the reactivation session (Fig. 2G). An ANOVA (Group by Trial) revealed no significant effect of Group $\left(F_{(1,11)}=0.01\right)$ or Trial $\left(F_{(1,11)}=0.51\right)$. Similarly, both Vehicle- and c646-treated rats exhibited equivalently high levels of freezing during the "PR"-STM test $\left(t_{(11)}=\right.$ $0.88)($ Fig. $2 \mathrm{H})$ and the "PR"-LTM test $\left(t_{(11)}=1.34\right)($ Fig. $2 \mathrm{H})$, indicating that c646 is only effective at impairing a fear memory in a reconsolidation paradigm if administered around the time of memory recall.

The reconsolidation deficit induced by c646 is not sensitive to spontaneous recovery, reinstatement, or to a shift in testing context

Previous studies have shown that amygdala-dependent fear memories that are lost due to interference with the reconsolidation process are lost in an enduring manner; they are not sensitive to spontaneous recovery, reinstatement, or renewal in a new testing context (Debiec and Ledoux 2004; Duvarci and Nader 2004; Kindt et al. 2009; Maddox and Schafe 2011a, b). Here, we asked whether the reconsolidation deficit induced by c646 is similarly insensitive to spontaneous recovery, reinstatement, or to a shift in the testing context. Rats were fear-conditioned as before, followed $24 \mathrm{~h}$ later by a reactivation trial in a distinct context (Chamber B). One hour later, rats were given intra-LA infusion of either Vehicle $(0.5 \mu \mathrm{L} /$ side) or c646 $(500 \mathrm{ng} /$ side; $0.5 \mu \mathrm{L})$ followed 3 and $21 \mathrm{~h}$ later by tests of PR-STM and PR-LTM in Chamber B. One week later, rats were retested for spontaneous recovery of the fear memory in Chamber B. The next day, rats underwent a fear reinstatement session in a novel context (Chamber C) consisting of exposure to three unsignaled footshocks (Duvarci and Nader 2004) followed $24 \mathrm{~h}$ later by a third test of fear memory in Chamber B (Reinstatement Test). Finally, rats were placed in another novel context (Chamber D) and tested with three tone CS presentations to examine whether fear to the tone re-emerges when the animals are tested outside of the original reconsolidation testing context (Context Shift) (Fig. 3A).

During the original reactivation session, both groups showed equivalently high levels of memory retrieval (Fig. 3B); the ANOVA (Group by Trial) revealed a significant main effect of Trial (preCS vs. CS; $\left.F_{(1,10)}=2464.11, P<0.01\right)$ but not of $\operatorname{Group}\left(F_{(1,10)}=\right.$ 0.04). Furthermore, consistent with our previous experiments, c646-treated rats showed intact memory during the PR-STM test $\left(t_{(10)}=1.51\right)$, but impaired memory retention during the PR-LTM test $\left(t_{(10)}=6.21, P<0.01\right)$ (Fig. 3C). Importantly, during the test of spontaneous recovery 1 wk later, c646-treated rats continued to exhibit memory impairment while the Vehicle control group exhibited high levels of retention $\left(t_{(10)}=6.55, P<0.01\right)$ (Fig. 3D). During the reinstatement session administered on the next day, both groups exhibited significant post-shock freezing in Chamber C (data not shown). An ANOVA (Group by Trial) revealed a significant main effect of Trial (pre-shock vs. post-shock period; $\left.F_{(3,30)}=503.91, P<0.01\right)$ but not of Group $\left(F_{(1,10)}=\right.$
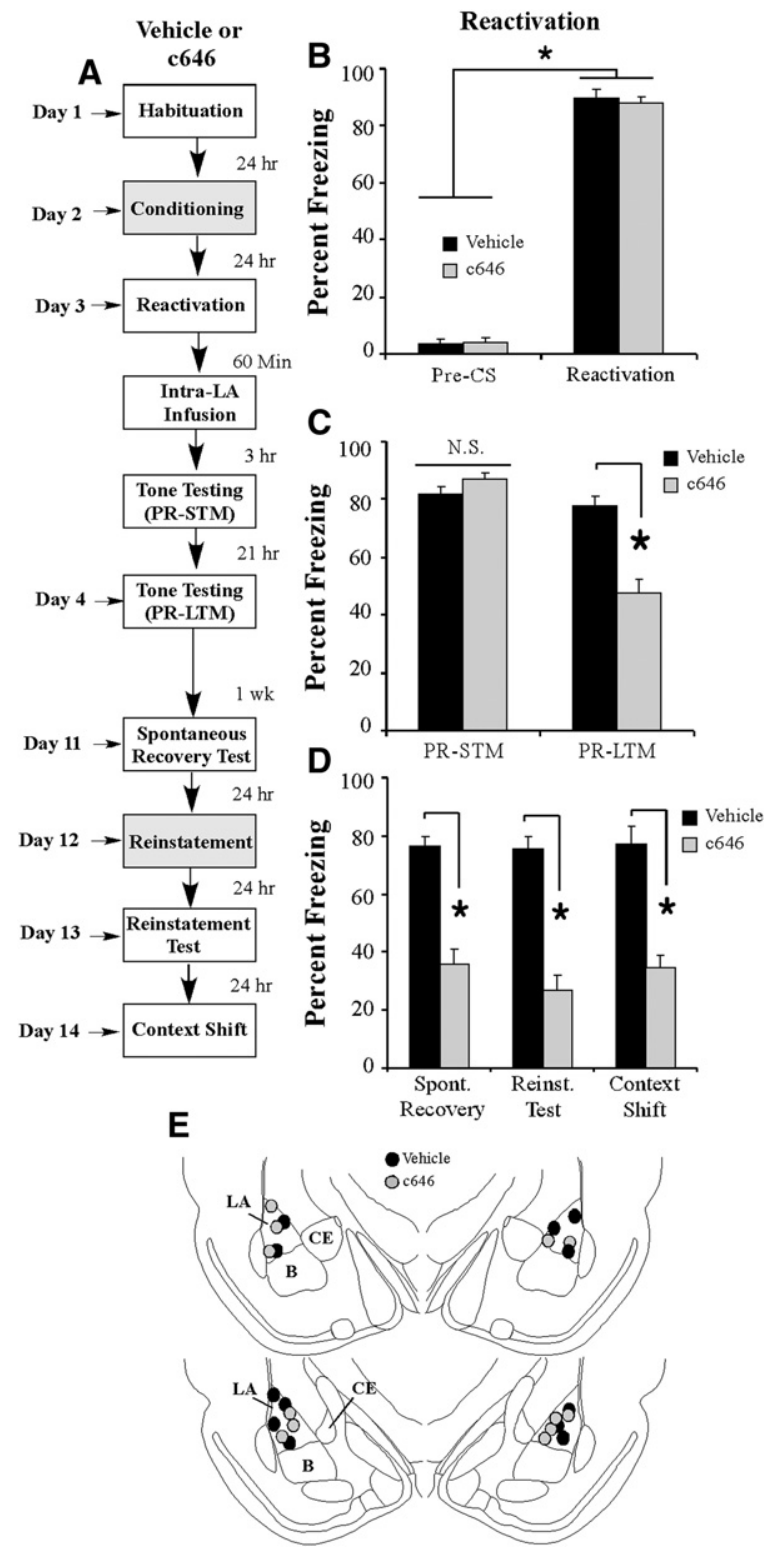

Figure 3. The reconsolidation deficit induced by c646 is not sensitive to spontaneous recovery, reinstatement, or to a shift in testing context. ( $A$ ) Schematic of the behavioral protocol (see text for details). (B) Memory retrieval data for rats given intra-LA infusion of Vehicle $(n=6)$ or c646 $(n=$ 6). $\left({ }^{*}\right) P<0.05$ relative to the pre-CS period. (C) Mean ( \pm SEM) percent freezing during the PR-STM and PR-LTM tests in Vehicle- and c646-infused rats. $\left.{ }^{*}\right) P<0.05$ relative to Vehicle-infused controls. $(D)$ Mean $( \pm$ SEM) percent freezing during the spontaneous recovery, reinstatement, and context shift tests. (E) Cannula placements for rats infused with either Vehicle (black circles) or c646 (gray circles). (*) $P<0.05$ relative to Vehicle-infused controls.

0.12 ), indicating an increase in freezing relative to the pre-shock period in both groups. When retested $24 \mathrm{~h}$ later for evidence of reinstatement of fear in Chamber B, however, c646-treated rats continued to exhibit memory impairment while the Vehicle group exhibited high levels of freezing $\left(t_{(10)}=9.68, P<0.01\right)$ (Fig. 3D), suggesting that the c646-induced reconsolidation deficit is not sensitive to reinstatement following exposure to an aversive event equivalent in strength to the original aversive experience. Finally, during the context shift test in Chamber D, c646-treated rats 
continued to exhibit memory impairment while the Vehicle group exhibited high levels of freezing $\left(t_{(10)}=5.73, P<0.01\right)$, suggesting that fear memories that are lost following treatment with c646 in a reconsolidation paradigm do not re-emerge in a different testing context (Fig. 3D).

\section{p300/CBP HAT activity is required for the reconsolidation of an older fear memory}

In each of our previous experiments, we reactivated the fear memory within $24 \mathrm{~h}$ following training. We next asked whether c646 can impair the reconsolidation of an older, "well-consolidated" memory. Rats were fear-conditioned as before followed 2 wk later by a memory reactivation trial and intra-LA infusion of either Vehicle $(0.5 \mu \mathrm{L} /$ side $)$ or c646 $(500 \mathrm{ng} /$ side; $0.5 \mu \mathrm{L})$ (Fig. $4 \mathrm{~A})$. Both groups showed equivalently high levels of freezing during the reactivation session (Fig. 4B); an ANOVA (Group by Trial) revealed a significant main effect of Trial (pre-CS vs. CS; $F_{(1,9)}=$ $4902.99, P<0.01)$ but not of Group $\left(F_{(1,9)}=0.76\right)$. Three hours following memory reactivation and drug infusion, both Vehicleand c646-infused groups displayed equivalent levels of freezing during the PR-STM test $\left(t_{(9)}=0.15\right)$ (Fig. 4C). On the following day, however, c646-treated rats exhibited impaired PR-LTM relative to the Vehicle-infused controls $\left(t_{(9)}=8.66, P<0.05\right)$ (Fig. $4 C)$. Thus, pharmacological inhibition of p300/CBP HAT activity in the LA can effectively impair the reconsolidation of even older, "well-consolidated" fear memories.

p300/CBP HAT activity is required for the consolidation and reconsolidation of memory-related neural plasticity in the LA

In a final series of experiments, we asked whether p300/CBP HAT activity is required for the consolidation and reconsolidation of training-related enhancements in tone-evoked neural activity in the LA, a neurophysiological correlate of fear conditioning
(Quirk et al. 1995; Rogan et al. 1997). In our first experiment, rats were fear-conditioned with three pairings of a modified tone CS with footshock (see Materials and Methods) followed $1 \mathrm{~h}$ later by intra-LA infusion of Vehicle $(0.5 \mu \mathrm{L} /$ side $)$ or c 646 $(500 \mathrm{ng} /$ side; $0.5 \mu \mathrm{L})$. All rats then received tests of STM and LTM 3 and $21 \mathrm{~h}$ later, while auditory-evoked field potentials (AEFPs) were recorded from the LA (Fig. 5A). As in our previous experiments, we found that intra-LA infusion of c646 had no effect on STM $\left(t_{(13)}=0.02\right)$ (Fig. $5 \mathrm{~B}$ ) yet significantly impaired LTM $\left(t_{(13)}=12.59, P<0.01\right)$ relative to Vehicle-infused controls (Fig. 5B). Similarly, analysis of the neurophysiological data revealed that both Vehicle- and c646-infused rats exhibited significant enhancements in the amplitude of the short-latency component $(\sim 12-16 \mathrm{msec})$ of the AEFP in the LA during the STM test relative to baseline (Vehicle: $t_{(7)}=4.65, P<0.05$; c646: $t_{(6)}=9.63, P<$ $0.05)$ that did not differ from each other $\left(t_{(13)}=0.30\right)$ (Fig. $5 \mathrm{C}$ ). However, during the LTM test, c646-treated rats exhibited significantly less AEFP amplitude change relative to Vehicle-infused controls $\left(t_{(13)}=3.63, P<0.05\right)$ (Fig. 5C). Thus, intra-LA infusion of c646 shortly following training can significantly impair, in parallel, both the consolidation of a fear memory and the consolidation of training-related neural plasticity in the LA.

\section{Intra-LA infusion of c646 shortly after fear memory retrieval impairs memory-related neural plasticity in the $L A$}

Next, we examined the effect of post-retrieval infusions of c 646 on memory-related neural plasticity in the LA (Doyère et al. 2007). Rats were fear-conditioned as before followed $24 \mathrm{~h}$ later by a reactivation session consisting of a single presentation of a modified tone CS (see Materials and Methods). One hour following the reactivation session, rats received intra-LA infusion of either Vehicle $(0.5 \mu \mathrm{L} /$ side) or c646 (500 ng/side; $0.5 \mu \mathrm{L})$ followed 3 and $21 \mathrm{~h}$ later by tests of PR-STM and PR-LTM while AEFPs were recorded from the LA (Fig. 6A). Analysis of the reactivation session data revealed that both Vehicle- and c646-infused rats exhibited significant and equivalent memory recall during the reactivation session; the ANOVA (Group by Trial) revealed a significant effect of Trial (pre-CS vs. CS; $F_{(1,9)}=$ 1280.83, $P<0.05)$, but not of Group $\left(F_{(1,9)}=0.25\right)$ (Fig. 6B). Furthermore, as in our previous experiments, we found that intra-LA infusion of c646 had no effect on PR-STM $\left(t_{(9)}=0.20\right)$ (Fig. 6C) but significantly impaired PR-LTM relative to Vehicle-infused controls $\left(t_{(9)}=7.90, P<0.01\right)$ (Fig. 6C). Analysis of the neurophysiology revealed that both Vehicle- and c646infused rats exhibited significant retention of training-related enhancements in the amplitude of the AEFP in the LA during the PR-STM test relative to baseline (Vehicle: $t_{(4)}=5.83, P<0.05$; c646: $\left.t_{(5)}=3.88, P<0.05\right)$ that did not differ from each other $\left(t_{(9)}=0.45\right.$ ) (Fig. 6D). However, during the PR-LTM test, c646-treated rats exhibited significantly less AEFP amplitude change relative to Vehicleinfused controls $\left(t_{(9)}=2.47, P<0.05\right)$ (Fig. 6D). Thus, intra-LA infusion of c646 shortly following fear memory retrieval significantly impairs the reconsolidation of a fear memory and, in 


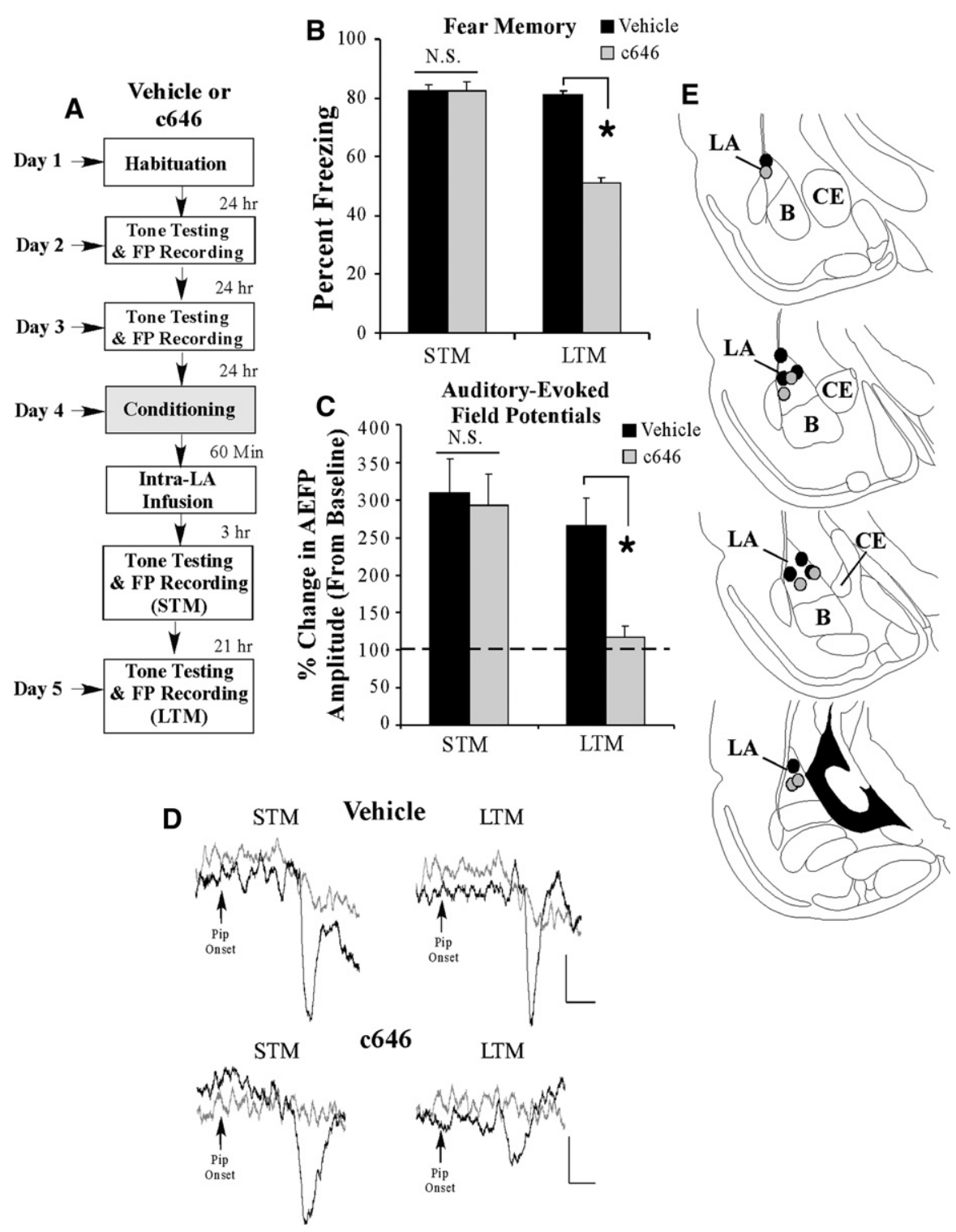

Figure 5. Intra-LA infusion of an inhibitor of p300/CBP activity impairs fear memory consolidation and the consolidation of training-related neural plasticity in the LA. (A) Rats were given two baseline AEFP recording sessions on separate days followed by fear conditioning with three tone-pip-shock pairings followed $1 \mathrm{~h}$ later by intra-LA infusion of either Vehicle $(n=8)$ or c646 (500 ng/side; $n=7)$. Rats in each group were then tested for STM and LTM 3 and $21 \mathrm{~h}$ later while AEFPs were recorded from the LA. $(B)$ Mean ( \pm SEM) percent freezing during the STM and LTM tests in Vehicle- and c646-infused groups. (C) Mean ( \pm SEM) percent of change in AEFP amplitude during the STM and LTM tests in Vehicle- and c646-infused rats, relative to baseline. $\left({ }^{*}\right) P<0.05$ relative to Vehicle-infused controls. $(D)$ Representative AEFPs recorded from the LA for each group during baseline (light gray trace), STM and LTM sessions (darker traces). Scale bar, $10 \mu \mathrm{V}, 5 \mathrm{msec}$. (E) Electrode placements for rats infused with either Vehicle (black circles) or c646 (gray circles).

parallel, leads to a reversal in training-related enhancements in tone-evoked neural activity in the LA.

Importantly, we found that the effect of c646 on memory-related neural plasticity is specific to fear memory retrieval. In a separate experiment, rats were fear-conditioned as before followed 24 h later by a "no-reactivation" session in which they were placed in the testing chamber without a CS presentation. One hour following the "no-reactivation" session, rats received intra-LA infusion of either Vehicle $(0.5 \mu \mathrm{L} /$ side $)$ or c646 $(500 \mathrm{ng} / \mathrm{side}$; $0.5 \mu \mathrm{L}$ ) followed 3 and $21 \mathrm{~h}$ later by tests of "PR"-STM and
"PR"-LTM (Fig. 7A). As expected, analysis of the "no-reactivation" session data revealed that both groups displayed equivalently low levels of freezing during the "pre-CS" period and during the 20-sec period when the CS would have been presented during the reactivation session (Fig. 7B). An ANOVA (Group by Trial) revealed no significant effect of Group $\left(F_{(1,11)}=0.04\right)$ or Trial $\left(F_{(1,11)}=\right.$ $0.01)$. Similarly, both Vehicle- and c646-treated rats exhibited equivalently high levels of freezing during the "PR"-STM test $\left(t_{(11)}=1.02\right)$ (Fig. 7C) and during the "PR"-LTM test $\left(t_{(11)}=\right.$ 0.14 ) (Fig. 7C). Analysis of the neurophysiology revealed that both Vehicleand c646-infused rats exhibited significant enhancements in AEFP amplitude relative to baseline during the "PR"-STM test (Vehicle: $t_{(6)}=12.20$, $P<0.05 ;$ c646: $\left.t_{(5)}=5.81, P<0.05\right)$ that did not differ from each other ("PR"-STM: $t_{(11)}=0.08$ ) (Fig. 7D). Furthermore, we observed no differences in AEFP amplitude between the two groups during the PR-LTM test $\left(t_{(11)}=\right.$ 0.18) (Fig. 7D). Thus, c646 is only effective at impairing memory-associated neural plasticity when it is administered around the time of memory recall.

\section{Discussion}

Epigenetic mechanisms, including modifications in chromatin structure, have been widely studied in learning and memory processes, yet relatively little remains known about the role of chromatin modifications in amygdaladependent learning and memory. Recently, our laboratory has shown that auditory Pavlovian fear conditioning is associated with an increase in histone $\mathrm{H} 3$ acetylation in the LA (Monsey et al. 2011). Furthermore, we have observed that intra-LA infusion of an HDAC inhibitor enhances the consolidation of an auditory fear memory; that is, STM is not affected, while LTM is enhanced (Monsey et al. 2011). In the present study, we sought to systematically examine the role of p300/CBP HAT activity in fear memory consolidation and reconsolidation processes. We show that intra-LA infusion of a selective inhibitor of p300/CBP HAT activity impairs both training- and retrieval-related regulation of histone H3 acetylation in LA neurons. Furthermore, we show that pharmacological inhibition of p300/CBP HAT activity impairs both new and reactivated auditory fear memories and memory-associated neural plasticity in the LA.

The role of both CBP and p300 HAT activity in learning and memory has been most widely studied using hippocampaldependent memory paradigms (Korzus et al. 2004; Wood et al. 2005, 2006; Oliveira et al. 2007, 2011; Vecsey et al. 2007; Barrett 

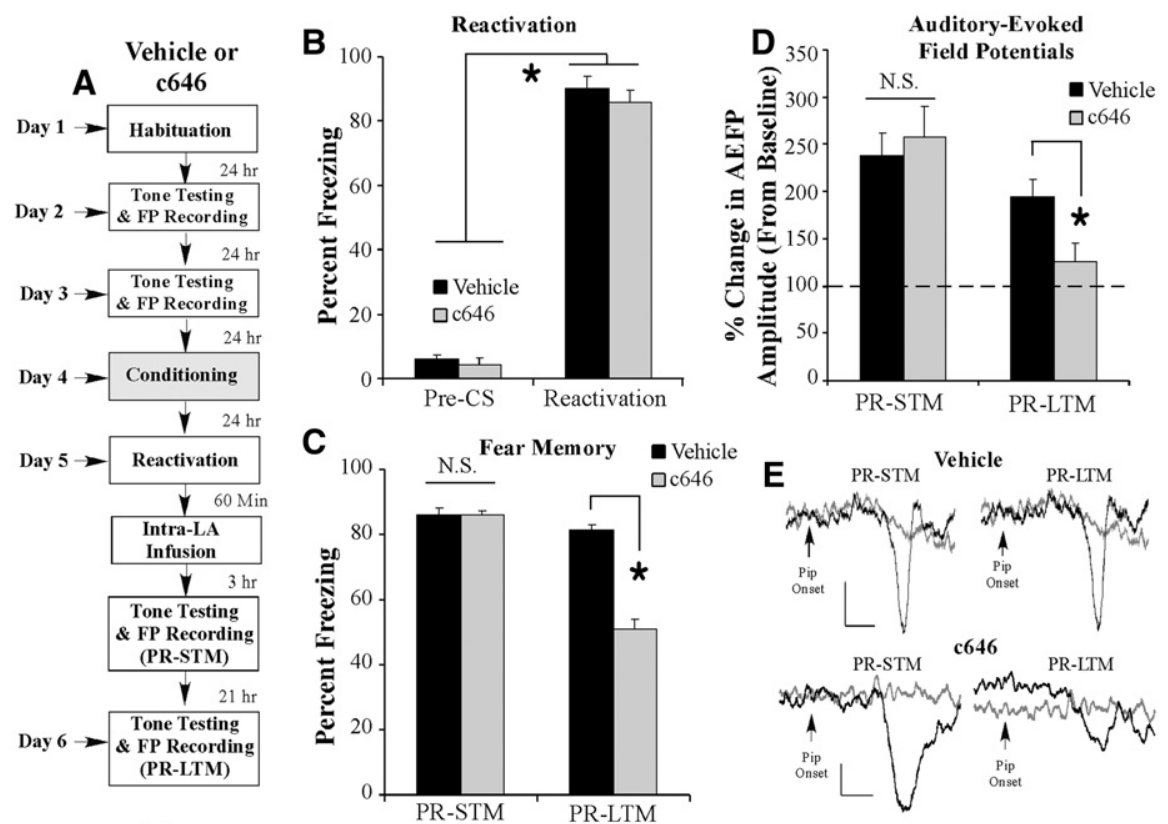

$\mathbf{F}$
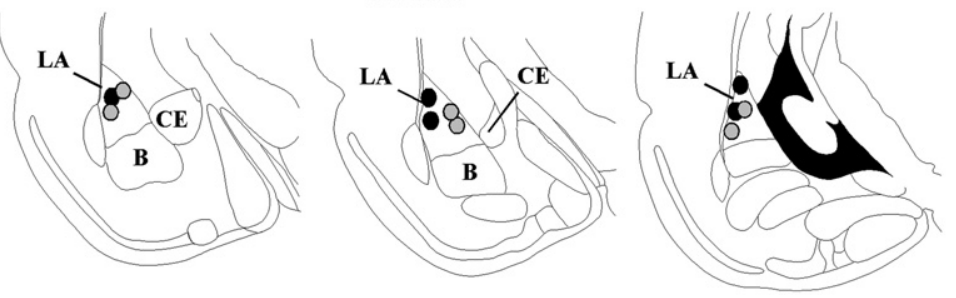

Figure 6. Intra-LA infusion of an inhibitor of p300/CBP activity impairs fear memory reconsolidation and memory-related neural plasticity in the LA. $(A)$ Rats were given two baseline AEFP recording sessions on separate days followed by fear conditioning with three tone-pip-shock pairings. Twenty-four hours following training, rats were given a memory reactivation session consisting of a single tone-pip CS presentation followed $1 \mathrm{~h}$ later by intra-LA infusions of Vehicle $(n=5)$ or c646 $(500 \mathrm{ng} / \mathrm{side} ; n=6)$. Rats in each group were then tested for PR-STM and PR-LTM 3 and $21 \mathrm{~h}$ later while AEFPs were recorded from the LA. (B) Memory retrieval data for the Vehicle- and c646-infused groups. $\left.{ }^{*}\right) P<0.05$ relative to the pre-CS period. (C) Mean ( \pm SEM) percent freezing during the PR-STM and PR-LTM tests in Vehicle- and c646-infused groups. $(D)$ Mean $( \pm$ SEM) percent of change in AEFP amplitude during the PR-STM and PR-LTM tests in Vehicle- and c646l-infused rats, relative to baseline. $\left(^{*}\right) P<0.05$ relative to Vehicle-infused controls. ( $E$ ) Representative AEFPs recorded from the LA for each group during baseline (light gray trace), PR-STM and PR-LTM sessions (darker traces). Scale bar, $10 \mu \mathrm{V}, 5 \mathrm{msec}$. ( $F$ ) Electrode placements for rats infused with either Vehicle (black circles) or c646 (gray circles).

tory fear memory; STM is intact, while LTM is significantly impaired. We further show that local infusion of c646 significantly impairs the consolidation of training-related neural plasticity in the LA; short-term enhancements in tone-evoked neural activity in the LA are intact, but return to baseline levels within $24 \mathrm{~h}$. Collectively, our findings suggest that p300/CBP HAT activity plays a critical role in fear memory consolidation and associated synaptic plasticity in the LA.

Our laboratory has also recently focused on the role of chromatinmodifying enzymes in the fear memory reconsolidation process. We have shown that retrieval of an auditory fear memory is associated with an increase in histone $\mathrm{H} 3$ acetylation in the LA (Maddox and Schafe 2011b). Furthermore, we have shown that intraLA infusion of an HDAC inhibitor enhances the reconsolidation of an auditory fear memory; that is, PR-STM is not affected, while PR-LTM is significantly enhanced (Maddox and Schafe 2011b). In the present study, we show that intra-LA infusion of the p300/ CBP HAT inhibitor c646 impairs retrieval-related regulation of histone $\mathrm{H} 3$ acetylation in the LA. Furthermore, intra-LA infusion of c646 following auditory fear memory retrieval was observed to interfere significantly with the reconsolidation of both recently acquired and "well-consolidated" (e.g., 2-wk-old) fear memories; that is, PR-LTM is impaired, while PR-STM is unaffected. Importantly, we observed that the effect of c646 on memory reconsolidation is specific to reactivated memories and temporally graded; there was no effect of c646 infusion in the absence of memory reactivation or following a delayed infusion. Further-

et al. 2011; Valor et al. 2011). These studies have complemented existing pharmacological studies that have implicated HAT and HDAC activity in hippocampal-dependent memory and synaptic plasticity (Levenson et al. 2004; Fischer et al. 2007; Vecsey et al. 2007; Miller et al. 2008; Guan et al. 2009; Stefanko et al. 2009; Zhao et al. 2010, 2012; Hawk et al. 2011). However, only two studies have to date implicated CBP in auditory fear conditioning in a genetically modified mouse model (Oike et al. 1999; Alarcon et al. 2004), while most have failed to find an effect (Korzus et al. 2004; Wood et al. 2005, 2006; Oliveira et al. 2007, 2011; Valor et al. 2011). However, given that both $\mathrm{CBP}$ and p300 share $\sim 90 \%$ sequence homology (Wang et al. 2008), it has been suggested that each of these HATs may compensate for one another during the formation of certain types of memory (Oliveira et al. 2011). If true, this might explain the lack of consistent findings with cued fear conditioning, which is typically considered more salient and robust relative to contextual fear. Indeed, in the present study we show that intra-LA infusion of c646, a pharmacological inhibitor that targets both p300 and CBP, significantly impairs training-related $\mathrm{H} 3$ acetylation and the consolidation of an audi- more, we show that memories lost following post-retrieval treatment with c646 are not subject to spontaneous recovery, to reinstatement following a series of unsignaled footshocks, or to a shift in the testing context, all of which are trademark characteristics of extinguished fear memories (Pavlov 1927; Bouton and Bolles 1979; Bouton and Ricker 1994). This latter finding rules out the possibility that c646 may have influenced fear memory reconsolidation processes by promoting facilitated extinction after the reactivation trial. This finding is particularly important in light of a recent report suggesting that infusion of c646 into the prefrontal cortex can paradoxically enhance fear extinction (Marek et al. 2011). Our findings, in contrast, suggest that fear extinction has not been enhanced by c646; rather, local infusion of c646 into the LA following retrieval appears to have specifically interfered with fear memory reconsolidation, a finding that complements that of a recent study in the crab Chasmagnathus (Federman et al. 2012).

While our findings suggest that treatment with an inhibitor of p300/CBP activity can impair fear memory consolidation and reconsolidation in the LA, a number of outstanding questions 


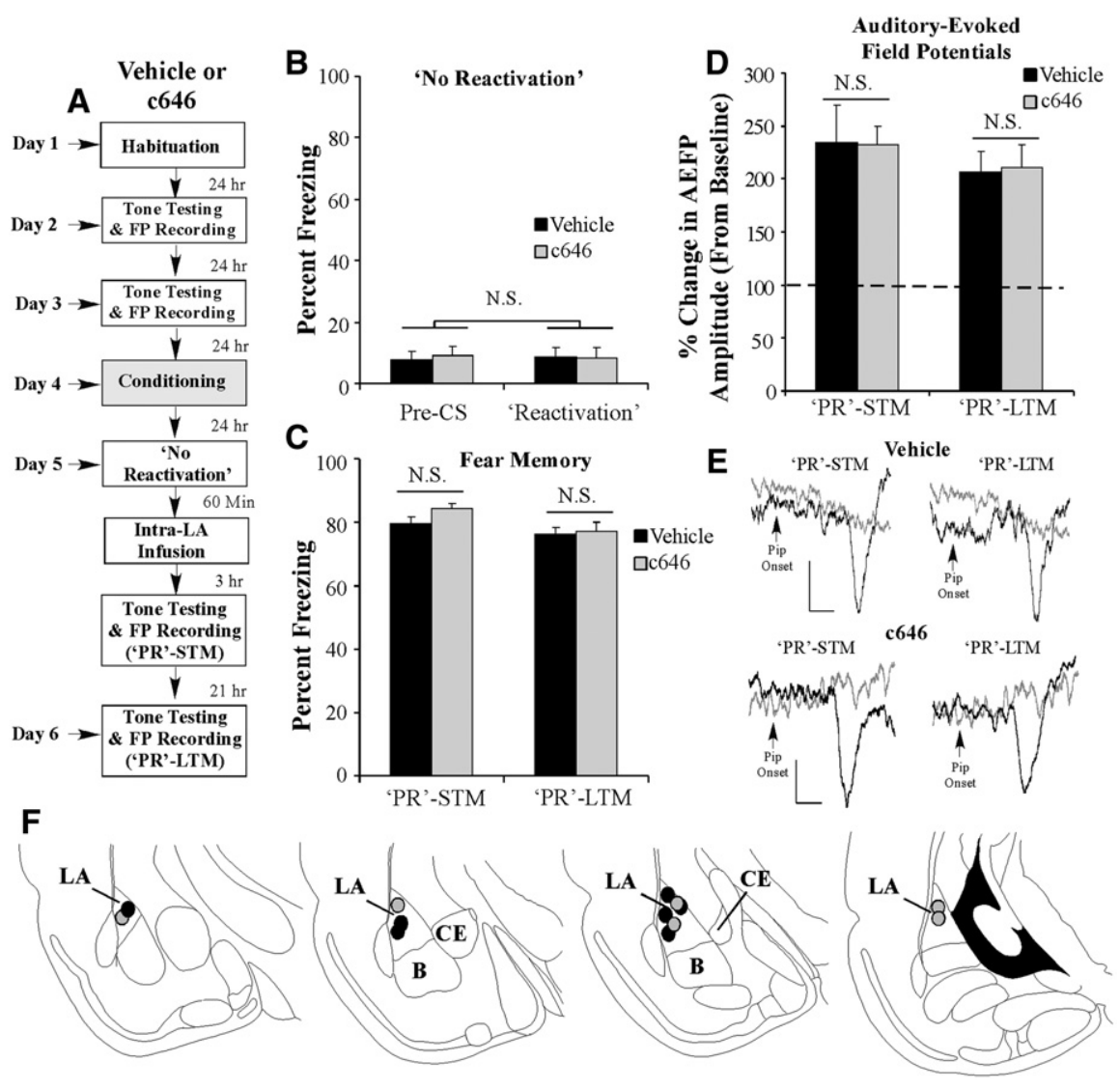

Figure 7. Intra-LA infusion of an inhibitor of $\mathrm{p} 300 / \mathrm{CBP}$ activity in the absence of fear memory retrieval has no effect on fear memory reconsolidation or memory-related neural plasticity in the LA. $(A)$ Rats were given two baseline AEFP recording sessions on separate days followed by fear conditioning with three tone-pip-shock pairings. Twenty-four hours following training, rats were given a "no-reactivation" session followed by infusion of Vehicle $(n=7)$ or c646 (500 ng/side; $n=6)$. Rats in each group were then tested for "PR" -STM and "PR"-LTM 3 and $21 \mathrm{~h}$ later while AEFPs were recorded from the LA. (B) Memory retrieval data for the Vehicle- and c646-infused groups. (C) Mean ( \pm SEM) percent freezing during the "PR"-STM and "PR"-LTM tests in Vehicle- and c646-infused groups. (D) Mean ( \pm SEM) percent of change in AEFP amplitude during the "PR"-STM and "PR"-LTM tests in Vehicle- and c646-infused rats, relative to baseline. (E) Representative AEFPs recorded from the LA for each group during baseline (light gray trace), "PR"-STM and "PR"-LTM sessions (darker traces). Scale bar, $10 \mu \mathrm{V}, 5$ msec. (F) Electrode placements for rats infused with either Vehicle (black circles) or c646 (gray circles).

remain. First, given that c646 is a relatively new and not yet fully characterized compound, the potential for off-target effects exists (Bowers et al. 2010; Marek et al. 2011). Second, to our knowledge, no pharmacological inhibitors have been identified that can inhibit the HAT activity of p300 without interfering with CBP. Accordingly, in the present study, we cannot distinguish between the roles of CBP and p300 in fear memory consolidation processes. Furthermore, previous work has suggested that p300/CBP and PCAF can structurally associate with each another to regulate histone acetylation (Bannister and Kouzarides 1996; Reid et al 1998; Schiltz et al. 1999), suggesting that inhibition of p300/ CBP may also impair the HAT activity of PCAF, a hypothesis not yet tested. Interestingly, previous work has suggested that these HATs may differ in the histones and lysine residues they preferentially acetylate (McManus and Hendzel 2003; Kouzarides 2007). For example, it has been suggested that CBP may preferentially regulate the acetylation of histones $\mathrm{H} 2 \mathrm{~A}$ and $\mathrm{H} 2 \mathrm{~B}$ over histone H3 and H4 (Alarcon et al. 2004; Valor et al. 2011), whereas p300 has been shown to acetylate all four core histones but with some preference for H3 and H4 (Ogryzko et al. 1996; Schiltz et al. 1999). These findings suggest there may be potential functional differences between these HATs, allowing each to make a different contribution to transcriptional control during memory formation. Future work will be required to examine the role of specific HATs and the core histones they regulate during fear memory consolidation processes.

In summary, the results of the present work provide strong evidence that p300/CBP HAT activity is critical for auditory fear memory consolidation and reconsolidation within the LA. Our findings represent the first comprehensive look at the role of p300/CBP HAT activity in amygdala-dependent learning and memory and associated synaptic plasticity, and make an additional contribution toward our understanding of the role of epigenetic mechanisms in the regulation of memory and synaptic plasticity in the mammalian brain.

\section{Materials and Methods}

\section{Subjects}

Adult-male Sprague-Dawley rats (Harlan), weighing 300-350 g and aged 2$3 \mathrm{mo}$, were housed individually in plastic cages and maintained on a 12:12-h light/dark cycle with food and water provided ad libitum.

\section{Surgery}

Rats were anesthetized with i.p. administration of ketamine $(100 \mathrm{mg} / \mathrm{kg})$ and xylazine $(6.0 \mathrm{mg} / \mathrm{kg})$ and implanted with 26-gauge stainless-steel guide cannulas (Plastics One) in the LA $(-3.2 \mathrm{~mm}, \pm 5.2 \mathrm{~mm},-8.0 \mathrm{~mm}$ relative to bregma). Guide cannulas were secured to screws in the skull using a mixture of dental acrylic and cement, and 31-gauge dummy cannulas were inserted into the guide to prevent obstruction. Buprenex $(0.2 \mathrm{mg} / \mathrm{kg})$ was administered as an analgesic, and rats were provided with at least $5 \mathrm{~d}$ post-operative recovery time. All surgical procedures were conducted under the guidelines provided in the National Institutes of Health Guide for the Care and Use of Experimental Rats and were approved by the Yale University Institutional Animal Care and Use Committee.

\section{Electrode implantation procedures}

Rats were anesthetized under the same procedures as those used for cannula implantation. Rats were implanted in the left LA with a tungsten recording electrode $(0.1 \mathrm{~mm}$ diameter, $1 \mathrm{M} \Omega)$ adhered to a 26-gauge guide cannula (AP: $-3.2 \mathrm{~mm}$; ML: \pm 5.2 ; DV: $-7.4)$. The recording wire extended $0.75 \mathrm{~mm}$ beyond the base of the guide. A 26-gauge guide cannula was implanted in the right-LA. A low-impedance copper wire was connected to a stainless steel bone screw drilled into the skull contralateral to the side of the recording electrode $\sim 1 \mathrm{~mm}$ posterior to bregma to serve as the reference for recording purposes. Another stainless steel screw attached to a copper wire was drilled into the skull $\sim 3 \mathrm{~mm}$ posterior to lambda and served as the ground electrode. Dental cement was used to anchor the electrodes and connecting device to the 
skull. Rats were given at least $5 \mathrm{~d}$ to recover from the surgery before experiments.

\section{Drugs}

The p300/CBP HAT inhibitor c646 (EMD Chemicals; 382113) was dissolved in $100 \%$ DMSO to a $2 \mu \mathrm{g} / \mu \mathrm{L}$ stock solution and then diluted in ACSF to a final $1 \mu \mathrm{g} / \mu \mathrm{L}$ solution, for intra-LA infusions of $500 \mathrm{ng}$ in $0.5 \mu \mathrm{L} /$ side. Vehicle solutions for intra-LA infusions consisted of $50 \%$ DMSO in ACSF.

\section{Pharmacology and Western blotting experiments}

For Western blotting experiments examining the effect of HAT activity inhibition on training-related regulation of histone acetylation, cannulated rats were habituated to handling and the conditioning chambers (30 $\mathrm{min} /$ day/chamber) for $4 \mathrm{~d}$ before auditory fear conditioning consisting of three tone-shock pairings ( $30 \mathrm{sec}, 5 \mathrm{kHz}, 75 \mathrm{~dB} ; 1.0 \mathrm{~mA}$ ). The conditioning chamber (Chamber A) was a lit chamber with a grid floor. One hour after tone-shock pairings, rats were infused with either the HAT inhibitor c646 (500 ng/side) or Vehicle $(0.5 \mu \mathrm{L} /$ side). Thirty minutes later (90 min following training), rats were given an overdose of chloral hydrate $(600 \mathrm{mg} / \mathrm{kg}$; i.p.), and brains were removed and frozen at $-80^{\circ} \mathrm{C}$ until processed. An additional group of "Naive-Vehicle" rats was handled and habituated but not exposed to the training chamber before infusion of Vehicle $(0.5 \mu \mathrm{L} /$ side $)$ and were sacrificed $30 \mathrm{~min}$ following infusions.

Western blotting experiments examining the effect of infusions of HAT inhibition on retrieval-induced changes in histone acetylation were conducted as above with the addition of habituation to the reactivation context (Context B), consisting of a dark chamber with a black plastic floor, which was washed immediately before reactivation with a distinctive peppermint soap. On the fifth day, they were given three tone-shock pairings in Chamber A. The next day, rats were given an auditory fear memory reactivation session consisting of a $30-\mathrm{sec}, 5-\mathrm{kHz}, 75-\mathrm{dB}$ tone that was administered in Chamber B. One hour later, rats were given intra-LA infusions of either c646 (500 ng/side) or Vehicle $(0.5 \mu \mathrm{L} /$ side). Thirty minutes later ( $90 \mathrm{~min}$ after the reactivation session), all rats were given an overdose of chloral hydrate $(600 \mathrm{mg} / \mathrm{kg}$; i.p.), and brains were removed and frozen at $-80^{\circ} \mathrm{C}$ until processed.

Punches containing the LA were obtained with a $1-\mathrm{mm}$ punch tool (Fine Science Tools) from $400-\mu \mathrm{m}$-thick sections taken on a sliding freezing microtome. Punches were manually dounced in $100 \mu \mathrm{L}$ of ice-cold hypotonic lysis buffer $(10 \mathrm{mM}$ Tris- $\mathrm{HCl}$ at $\mathrm{pH}$ 7.5, $1 \mathrm{mM}$ EDTA, $2.5 \mathrm{mM}$ sodium pyrophosphate, $1 \mathrm{mM}$ phenylmethylsulfonyl fluoride, $1 \mathrm{mM} \beta$-glycerophosphate, $1 \%$ Igepal CA-630, 1\% protease inhibitor cocktail [Sigma-Aldrich], and $1 \mathrm{mM}$ sodium orthovanadate). Sample buffer was immediately added to the homogenates, and the samples were boiled for 4 min. Homogenates were electrophoresed on $18 \%$ Tris- $\mathrm{HCl}$ gels and blotted to Immobilon-P (Millipore). Western blots were then blocked in TTBS buffer $(50 \mathrm{mM}$ Tris- $\mathrm{HCl}$ at $\mathrm{pH} 7.5,150 \mathrm{mM}$ $\mathrm{NaCl}$, and $0.05 \%$ Tween 20 ) with $5 \%$ dry milk and then incubated with the appropriate primary antibody (AcH3 [pan], 1:3000, Millipore; total H3, 1:5000, Millipore). Blots were then incubated with anti-rabbit antibody conjugated to horseradish peroxidase (Cell Signaling) and developed using West Dura chemiluminescent substrate (Pierce Laboratories). Western blots were developed in the linear range used for densitometry. Densitometry was conducted using Image J software. To control for inconsistencies in loading, optical densities for total histone protein were normalized to GAPDH protein (1:20,000; Abcam). Acetyl-histone proteins were then normalized to total histone protein, and finally, data were normalized to the average value of naive controls and analyzed using ANOVA.

\section{Behavioral experiments}

Rats were handled for $2 \mathrm{~d}$ before conditioning. On the second handling day, dummy cannulas were removed to check for patency. Rats were then habituated to Chamber A for 15 min (Day 1).
The following day (Day 2), rats were placed in Chamber A and presented with three tone-shock pairings consisting of a 30-sec, $5-\mathrm{kHz}, 75-\mathrm{dB}$ tone that coterminated with a $1-\mathrm{sec}, 1.0-\mathrm{mA}$ footshock. One hour later, rats received intra-LA infusion of either c646 (500 ng/side) or Vehicle $(0.5 \mu \mathrm{L} /$ side $)$. Infusions were made over $4 \mathrm{~min}$, and the infusion cannulas were left in place for at least 2 min following infusion to facilitate diffusion throughout the LA. Three hours after infusions, rats were tested for shortterm memory (STM) consisting of the presentation of three tones (30 sec, $5 \mathrm{kHz}, 75 \mathrm{~dB}$ ) in Context B. Twenty-four hours later (Day 3 ), all rats received a long-term memory (LTM) test, which consisted of 10 tone presentations $(30 \mathrm{sec}, 5 \mathrm{kHz}, 75 \mathrm{~dB}$ ) and was conducted in Context B.

For the reconsolidation experiments, rats were habituated as before. On Day 2, rats received three tone-shock pairings consisting of a 30-sec, 5-kHz, 75-dB tone that coterminated with a 1-sec, 1.0-mA footshock. The next day (Day 3), rats were placed in Chamber B and received either a single tone presentation, to serve as a memory reactivation trial, or no tone presentation, to serve as a "no-reactivation" trial. One hour later, rats received intra-LA infusion of either c646 (500 ng/side) or Vehicle $(0.5 \mu \mathrm{L} /$ side $)$. Three hours after infusions, rats were tested for post-reactivation shortterm memory (PR-STM) consisting of the presentation of three tones (30 sec, $5 \mathrm{kHz}, 75 \mathrm{~dB}$ ) in Context B. Twenty-four hours later (Day 3), all rats received a post-reactivation long-term memory (PR-LTM) test, which consisted of 10 tone presentations (30 sec, $5 \mathrm{kHz}, 75 \mathrm{~dB}$ ) and was conducted in Context B. Rats used to examine the effect of HAT inhibition on the reconsolidation of a "wellconsolidated" memory were tested under identical parameters; however, they were returned to their home cage for $2 \mathrm{wk}$ following conditioning before reactivation, intra-LA infusions, and the subsequent PR-STM and PR-LTM tests.

An additional behavioral experiment examined whether the reconsolidation deficit induced by HAT inhibition in the LA was sensitive to spontaneous recovery, reinstatement, or to a shift in the testing context. Rats in this experiment were trained in Chamber A and reactivated $24 \mathrm{~h}$ later in Chamber B and given intra-LA infusions of c646 or Vehicle as described above. Twentyfour hours after reactivation, rats were returned to Chamber B and tested for PR-LTM, as described above. One week after the initial PR-LTM test, rats were returned to Chamber B and tested for spontaneous recovery with five tone presentations. The next day, they were placed in a novel context (Chamber C), scented with cedar and brightly illuminated, and given a reinstatement session consisting of three unsignaled footshocks ( $1 \mathrm{sec}, 1.0 \mathrm{~mA}$ ). Twenty-four hours later, all rats were returned to Chamber B and tested for reinstatement with five tone presentations. The next day, rats were introduced to a final novel context (Chamber D), consisting of a lit behavior box with a scented cotton-padded floor, and tested with three tone presentations to examine the context generality of the reconsolidation deficit.

Each behavioral test was videotaped for subsequent scoring and scored by an observer who was blind to the experimental conditions. Freezing was defined as a lack of movement, excluding that necessary for respiration, and was quantified as a percentage of the amount of time the rat spent engaged in freezing behavior during the CS presentations. All data were analyzed with ANOVA and Duncan's post-hoc t-tests. Repeated-measures ANOVAs were used for multiple trial comparisons. Differences were considered significant if $P<0.05$. Only data from those rats with bilaterally well-placed cannulas within the borders of the LA were included in the analyses.

\section{Neurophysiological recordings}

Awake-behaving neurophysiology took place in a custom-made electromagnetic-shielded recording chamber designed for delivery of auditory stimuli and recording. The chamber was kept within a ventilated and temperature-regulated acoustic isolation room. Stimulus delivery and data acquisition were controlled by SciWorks Experimenter Real-time 7.0 (DataWave). During recording, rats were exposed to a modified CS consisting of a series of tone "pips" (20 presentations of a $50-\mathrm{msec}, 75-\mathrm{dB}, 1-\mathrm{kHz}$ tone 
pips, delivered at a frequency of $1 \mathrm{~Hz}$ ) from a speaker mounted on the ceiling of the recording chamber. The tone pips were triggered by TTL signals generated by SciWorks. The TTL signals were converted (Coulbourn, H91-24, 5V TTL to $24 \mathrm{~V}$ converter) and sent to a tone generator (Coulbourn, H12-07, Seven-Tone Audio Cue). During recordings, the implanted electrodes were connected to a Micro-Miniature Headstage (DataWave). Neural signals were picked up (Legacy PCI data acquisition bundles, Model: DT3010), amplified (16-channel A-M Systems microelectrode amplifier, Model: AM-3600), and saved for off-line analysis.

On Day 1 of each experiment, rats were handled and habituated to the recording chamber and cable connection for $15 \mathrm{~min}$ each. On Days 2 and 3, baseline auditory-evoked field potentials (AEFPs) elicited by three presentations of the 20 tone-pip CS series were recorded (ITI $=2 \mathrm{~min}$ ) from the LA, for a total of 60 tone-pip presentations. On Day 4, rats received three tone-pip-shock pairings in an illuminated chamber consisting of a series of 20 tonepip presentations, which coterminated with a $1-\mathrm{sec}, 1.0-\mathrm{mA}$ footshock administered through the grid floor. One hour following training, rats received intra-LA infusion of either Vehicle $(0.5 \mu \mathrm{L} / \mathrm{side})$ or c646 $(500 \mathrm{ng} /$ side; $0.5 \mu \mathrm{L})$. Three hours later, rats were placed into a modified chamber that included a flat, black, peppermint-scented floor for STM testing, and AEFP recordings consisting of three presentations of the tone-pip CS series were recorded (ITI $=2 \mathrm{~min}$ ), for a total of 60 tone-pip presentations (identical to baseline recordings). The following day, rats were placed back in the modified chamber and examined for LTM with nine tone-pip presentations.

For the reconsolidation experiments, rats underwent habituation, baseline recording sessions, and fear conditioning as in the consolidation experiment. The next day (Day 5), rats were placed in the modified chamber (black, peppermint-scented floor) and received either a single tone-pip series presentation, to serve as a memory reactivation trial, or no tone-pip presentation, to serve as a "no-reactivation" trial. One hour later, rats were infused with either Vehicle $(0.5 \mu \mathrm{L} /$ side $)$ or c646 $(500 \mathrm{ng} /$ side; $0.5 \mu \mathrm{L})$. Three hours after infusions, rats were tested for PR-STM and AEFPs with three presentations of the tone-pip CS series, in the modified chamber. Twenty-one hours later (Day 6), rats were tested for PR-LTM and AEFPs with nine presentations of the tone-pip CS series.

Rats' freezing behavior was recorded during all sessions for off-line scoring. Following the completion of testing, all rats were rapidly and deeply anesthetized before transcardial perfusions and brain extractions for electrode placement analyses. For data analysis during STM/PR-STM sessions, all 60 AEFPs were averaged into a single waveform. Data analysis for the LTM/ PR-LTM sessions was conducted based on the average waveform from the last 60 AEFPs. Spike2 software (Cambridge Electronics Design) was used to analyze the amplitude of the short-latency negative-going component of the AEFP from the initial point of deflection to its maximal negativity, which occurs $\sim 12-16 \mathrm{msec}$ from the onset of the pip (Rogan et al. 1997; Schafe et al. 2005; Doyère et al. 2007). The amplitudes of AEFPs recorded during the STM and LTM tests were expressed as a percentage of the baseline amplitude for comparison between Vehicle- and c646-treated groups. Data were analyzed using $t$-tests, and differences were only considered significant if $P<0.05$.

\section{Acknowledgments}

This research was supported by National Institutes of Health Grant MH 073949 (to G.E.S.) and by Yale University.

\section{References}

Alarcon JM, Malleret G, Touzani K, Vronskaya S, Ishii S, Kandel ER, Barco A. 2004. Chromatin acetylation, memory, and LTP are impaired in $\mathrm{CBP}^{+/-}$mice: A model for the cognitive deficit in Rubinstein-Taybi syndrome and its amelioration. Neuron 42: 947-959.

Alberini CM. 2005. Mechanisms of memory stabilization: Are consolidation and reconsolidation similar or distinct processes? Trends Neurosci 28: 51-56.
Bannister AJ, Kouzarides T. 1996. The CBP co-activator is a histone acetyltransferase. Nature 384: 641-643.

Barco A, Bailey CH, Kandel ER. 2006. Common molecular mechanisms in explicit and implicit memory. J Neurochem 97: 1520-1533.

Barrett RM, Wood MA. 2008. Beyond transcription factors: The role of chromatin modifying enzymes in regulating transcription required for memory. Learn Mem 15: 460-467.

Barrett RM, Malvaez M, Kramar E, Matheos DP, Arrizon A, Cabrera SM, Lynch G, Greene RW, Wood MA. 2011. Hippocampal focal knockout of CBP affects specific histone modifications, long-term potentiation, and long-term memory. Neuropsychopharmacology 36: $1545-1556$.

Ben Mamou C, Gamache K, Nader K. 2006. NMDA receptors are critical for unleashing consolidated auditory fear memories. Nat Neurosci 9: $1237-1239$

Bouton ME, Bolles RC. 1979. Contextual control of the extinction of conditioned fear. Learn Motiv 10: 445-466.

Bouton ME, Ricker ST. 1994. Renewal of extinguished responding in a second context. Anim Learn Behav 22: 317-324.

Bowers EM, Yan G, Mukherjee C, Orry A, Wang L, Holbert MA, Crump NT, Hazzalin CA, Liszczak G, Yuan H, et al. 2010. Virtual ligand screening of the p300/CBP histone acetyltransferase: Identification of a selective small molecule inhibitor. Chem Biol 17: 471-482.

Debiec J, Ledoux JE. 2004. Disruption of reconsolidation but not consolidation of auditory fear conditioning by noradrenergic blockade in the amygdala. Neuroscience 129: 267-272.

Doyère V, Debiec J, Monfils MH, Schafe GE, LeDoux JE. 2007 Synapse-specific reconsolidation of distinct fear memories in the lateral amygdala. Nat Neurosci 10: 414-416.

Dudai Y, Eisenberg M. 2004. Rites of passage of the engram: Reconsolidation and the lingering consolidation hypothesis. Neuron 44: 93-100.

Duvarci S, Nader K. 2004. Characterization of fear memory reconsolidation. J Neurosci 24: 9269-9275.

Duvarci S, Nader K, LeDoux JE. 2005. Activation of extracellular signal-regulated kinase- mitogen-activated protein kinase cascade in the amygdala is required for memory reconsolidation of auditory fear conditioning. Eur J Neurosci 21: 283-289.

Duvarci S, Nader K, LeDoux JE. 2008. De novo mRNA synthesis is required for both consolidation and reconsolidation of fear memories in the amygdala. Learn Mem 15: 747-755.

Federman N, Fustinana MS, Romano A. 2012. Reconsolidation involves histone acetylation depending on the strength of the memory. Neuroscience 219: 145-156.

Fischer A, Sananbenesi F, Wang X, Dobbin M, Tsai LH. 2007. Recovery of learning and memory is associated with chromatin remodelling. Nature 447: $178-182$.

Guan JS, Haggarty SJ, Giacometti E, Dannenberg JH, Joseph N, Gao J, Nieland TJ, Zhou Y, Wang X, Mazitschek R, et al. 2009. HDAC2 negatively regulates memory formation and synaptic plasticity. Nature 459: $55-60$.

Hawk JD, Florian C, Abel T. 2011. Post-training intrahippocampal inhibition of class I histone deacetylases enhances long-term object-location memory. Learn Mem 18: 367-370.

Jiang Y, Langley B, Lubin FD, Renthal W, Wood MA, Yasui DH, Kumar A, Nestler EJ, Akbarian S, Beckel-Mitchener AC. 2008. Epigenetics in the nervous system. J Neurosci 28: 11753-11759.

Josselyn SA, Shi C, Carlezon WA Jr, Neve RL, Nestler EJ, Davis M. 2001. Long-term memory is facilitated by cAMP response element-binding protein overexpression in the amygdala. J Neurosci 21: 2404-2412.

Kindt M, Soeter M, Vervliet B. 2009. Beyond extinction: Erasing human fear responses and preventing the return of fear. Nat Neurosci 12: $256-258$.

Korzus E, Rosenfeld MG, Mayford M. 2004. CBP histone acetyltransferase activity is a critical component of memory consolidation. Neuron 42: 961-972.

Kouzarides T. 2007. Chromatin modifications and their function. Cell 128: $693-705$.

Levenson JM, Sweatt JD. 2005. Epigenetic mechanisms in memory formation. Nat Rev Neurosci 6: 108-118.

Levenson JM, Sweatt JD. 2006. Epigenetic mechanisms: A common theme in vertebrate and invertebrate memory formation. Cell Mol Life Sci 63: 1009-1016.

Levenson JM, O'Riordan KJ, Brown KD, Trinh MA, Molfese DL, Sweatt JD. 2004. Regulation of histone acetylation during memory formation in the hippocampus. J Biol Chem 279: 40545-40559.

Maddox SA, Schafe GE. 2011a. The activity-regulated cytoskeletal-associated protein (Arc/Arg3.1) is required for reconsolidation of a Pavlovian fear memory. J Neurosci 31: 7073-7082.

Maddox SA, Schafe GE. 2011b. Epigenetic alterations in the lateral amygdala are required for reconsolidation of a Pavlovian fear memory. Learn Mem 18: 579-593. 
Maddox SA, Monsey MS, Schafe GE. 2011. Early growth response gene 1 (Egr-1) is required for new and reactivated fear memories in the lateral amygdala. Learn Mem 18: 24-38.

Malkani S, Wallace KJ, Donley MP, Rosen JB. 2004. An egr-1 (zif268) antisense oligodeoxynucleotide infused into the amygdala disrupts fear conditioning. Learn Mem 11: 617-624.

Marek R, Coelho CM, Sullivan RK, Baker-Andresen D, Li X, Ratnu V, Dudley KJ, Meyers D, Mukherjee C, Cole PA, et al. 2011. Paradoxical enhancement of fear extinction memory and synaptic plasticity by inhibition of the histone acetyltransferase p300. J Neurosci 31: 7486-7491.

McManus KJ, Hendzel MJ. 2003. Quantitative analysis of CBP- and $\mathrm{P} 300$-induced histone acetylations in vivo using native chromatin. Mol Cell Biol 23: 7611-7627.

Miller CA, Campbell SL, Sweatt JD. 2008. DNA methylation and histone acetylation work in concert to regulate memory formation and synaptic plasticity. Neurobiol Learn Mem 89: 599-603.

Milner B, Squire LR, Kandel ER. 1998. Cognitive neuroscience and the study of memory. Neuron 20: $445-468$.

Miserendino MJ, Sananes CB, Melia KR, Davis M. 1990. Blocking of acquisition but not expression of conditioned fear-potentiated startle by NMDA antagonists in the amygdala. Nature 345: 716-718.

Moita MA, Lamprecht R, Nader K, LeDoux JE. 2002. A-kinase anchoring proteins in amygdala are involved in auditory fear memory. Nat Neurosci 5: 837-838.

Monsey MS, Ota KT, Akingbade IF, Hong ES, Schafe GE. 2011. Epigenetic alterations are critical for fear memory consolidation and synaptic plasticity in the lateral amygdala. PLOS ONE 6: e19958.

Ogryzko VV, Schiltz RL, Russanova V, Howard BH, Nakatani Y. 1996. The transcriptional coactivators p300 and CBP are histone acetyltransferases. Cell 87: 953-959.

Oike Y, Hata A, Mamiya T, Kaname T, Noda Y, Suzuki M, Yasue H, Nabeshima T, Araki K, Yamamura K. 1999. Truncated CBP protein leads to classical Rubinstein-Taybi syndrome phenotypes in mice: Implications for a dominant-negative mechanism. Hum Mol Genet 8: 387-396.

Oliveira AM, Wood MA, McDonough CB, Abel T. 2007. Transgenic mice expressing an inhibitory truncated form of p300 exhibit long-term memory deficits. Learn Mem 14: 564-572.

Oliveira AM, Estevez MA, Hawk JD, Grimes S, Brindle PK, Abel T. 2011. Subregion-specific p300 conditional knock-out mice exhibit long-term memory impairments. Learn Mem 18: 161-169.

Pavlov IP. 1927. Conditioned reflexes. Oxford University Press, London.

Ploski JE, Pierre VJ, Smucny J, Park K, Monsey MS, Overeem KA, Schafe GE. 2008. The activity-regulated cytoskeletal-associated protein (Arc/Arg3.1) is required for memory consolidation of Pavlovian fear conditioning in the lateral amygdala. J Neurosci 28: 12383-12395.

Ploski JE, Park KW, Ping J, Monsey MS, Schafe GE. 2010. Identification of plasticity-associated genes regulated by Pavlovian fear conditioning in the lateral amygdala. J Neurochem 112: 636-650.

Quirk GJ, Repa C, LeDoux JE. 1995. Fear conditioning enhances short-latency auditory responses of lateral amygdala neurons: Parallel recordings in the freely behaving rat. Neuron 15: 1029-1039.

Reid JL, Bannister AJ, Zegerman P, Martinez-Balbas MA, Kouzarides T. 1998. E1A directly binds and regulates the P/CAF acetyltransferase. EMBOJ 17: $4469-4477$.

Ressler KJ, Paschall G, Zhou XL, Davis M. 2002. Regulation of synaptic plasticity genes during consolidation of fear conditioning. J Neurosci 22: 7892-7902.

Rodrigues SM, Schafe GE, LeDoux JE. 2001. Intraamygdala blockade of the NR2B subunit of the NMDA receptor disrupts the acquisition but not the expression of fear conditioning. J Neurosci 21: $6889-6896$.
Rogan MT, Staubli UV, LeDoux JE. 1997. Fear conditioning induces associative long-term potentiation in the amygdala. Nature 390: 604-607.

Schafe GE, Nadel NV, Sullivan GM, Harris A, LeDoux JE. 1999. Memory consolidation for contextual and auditory fear conditioning is dependent on protein synthesis, PKA, and MAP kinase. Learn Mem 6: 97-110.

Schafe GE, Atkins CM, Swank MW, Bauer EP, Sweatt JD, LeDoux JE. 2000. Activation of ERK/MAP kinase in the amygdala is required for memory consolidation of Pavlovian fear conditioning. J Neurosci 20: 8177-8187.

Schafe GE, Doyère V, LeDoux JE. 2005. Tracking the fear engram: The lateral amygdala is an essential locus of fear memory storage. J Neurosci 25: 10010-10014.

Schiltz RL, Mizzen CA, Vassilev A, Cook RG, Allis CD, Nakatani Y. 1999. Overlapping but distinct patterns of histone acetylation by the human coactivators p300 and PCAF within nucleosomal substrates. J Biol Chem 274: $1189-1192$

Stefanko DP, Barrett RM, Ly AR, Reolon GK, Wood MA. 2009. Modulation of long-term memory for object recognition via HDAC inhibition. Proc Natl Acad Sci 106: 9447-9452.

Tronson NC, Taylor JR. 2007. Molecular mechanisms of memory reconsolidation. Nat Rev Neurosci 8: 262-275.

Tronson NC, Wiseman SL, Olausson P, Taylor JR. 2006. Bidirectional behavioral plasticity of memory reconsolidation depends on amygdalar protein kinase A. Nat Neurosci 9: 167-169.

Valor LM, Pulopulos MM, Jimenez-Minchan M, Olivares R, Lutz B, Barco A. 2011. Ablation of CBP in forebrain principal neurons causes modest memory and transcriptional defects and a dramatic reduction of histone acetylation but does not affect cell viability. J Neurosci 31: 1652-1663.

Varga-Weisz PD, Becker PB. 1998. Chromatin-remodeling factors: Machines that regulate? Curr Opin Cell Biol 10: 346-353.

Vecsey CG, Hawk JD, Lattal KM, Stein JM, Fabian SA, Attner MA, Cabrera SM, McDonough CB, Brindle PK, Abel T, et al. 2007. Histone deacetylase inhibitors enhance memory and synaptic plasticity via CREB:CBP-dependent transcriptional activation. J Neurosci 27: 6128-6140.

Wang L, Tang Y, Cole PA, Marmorstein R. 2008. Structure and chemistry of the p300/CBP and Rtt109 histone acetyltransferases: Implications for histone acetyltransferase evolution and function. Curr Opin Struct Biol 18: $741-747$.

Wood MA, Kaplan MP, Park A, Blanchard EJ, Oliveira AM, Lombardi TL, Abel T. 2005. Transgenic mice expressing a truncated form of CREB-binding protein (CBP) exhibit deficits in hippocampal synaptic plasticity and memory storage. Learn Mem 12: 111-119.

Wood MA, Attner MA, Oliveira AM, Brindle PK, Abel T. 2006. A transcription factor-binding domain of the coactivator CBP is essential for long-term memory and the expression of specific target genes. Learn Mem 13: 609-617.

Yang XJ, Seto E. 2007. HATs and HDACs: From structure, function and regulation to novel strategies for therapy and prevention. Oncogene 26: 5310-5318.

Zhao Z, Fan L, Frick KM. 2010. Epigenetic alterations regulate estradiol-induced enhancement of memory consolidation. Proc Natl Acad Sci 107: 5605-5610.

Zhao Z, Fan L, Fortress AM, Boulware MI, Frick KM. 2012. Hippocampal histone acetylation regulates object recognition and the estradiol-induced enhancement of object recognition. J Neurosci 32: 2344-2351.

Received October 26, 2012; accepted in revised form December 20, 2012. 


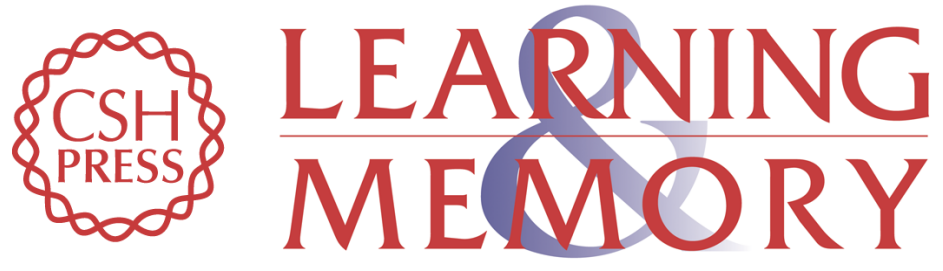

\section{p300/CBP histone acetyltransferase activity is required for newly acquired and reactivated fear memories in the lateral amygdala}

Stephanie A. Maddox, Casey S. Watts and Glenn E. Schafe

Learn. Mem. 2013, 20:

Access the most recent version at doi:10.1101/lm.029157.112

References This article cites 66 articles, 29 of which can be accessed free at: http://learnmem.cshlp.org/content/20/2/109.full.html\#ref-list-1

License

Email Alerting

Receive free email alerts when new articles cite this article - sign up in the box at the Service top right corner of the article or click here. 